\title{
Exploring Homogeneous Conditions for Mild Buchwald-Hartwig Amination in Batch and Flow
}

\author{
Saeed K. Kashani, Jacob E. Jessiman, Stephen G. Newman*
}

Centre for Catalysis Research and Innovation, Department of Chemistry and Biomolecular Sciences, University of Ottawa, Ottawa, Ontario, Canada, KıN 6N5

\begin{abstract}
Cross-couplings are among the most frequently used reactions in complex molecule synthesis. However, the requirement of stoichiometric base can cause challenges. Harsh, insoluble inorganic bases can lead to poor tolerance of sensitive functional groups, scale-up issues, and difficult adaptation to continuous flow platforms. Herein, we describe the use of high throughput experimentation to identify a number of conditions that enable Buchwald-Hartwig reactions to be carried out using readily available ligands (e.g. XantPhos) with DBU as a soluble, functional group tolerant, homogeneous base. Application of this system to diverse aminations in batch and flow are demonstrated, as is the translation of this technique to performing continuous Mizoroki-Heck and Sonogashira coupling reactions.
\end{abstract}

Performing chemical reactions continuously in microreactors ("flow chemistry) can provide benefits over batch synthesis, including improved safety at a range of temperatures and pressures, smaller reactor volumes, efficient scale-up, and waste reduction. ${ }^{1}$ A future where intelligent continuous flow systems can assist scientists in accessing and manufacturing complex molecules is particularly appealing. ${ }^{2}$ While this area is still in its infancy, recent examples in API manufacturing, on-demand synthesis, and automated optimization are promising..$^{-6}$ The propensity of solids to clog small reactor channels is one of the greatest challenges that must be overcome before continuous synthesis can become universally applicable. While numerous strategies have been reported,7 these solidhandling issues continue to hinder the progress and implementation of continuous flow methods.

Our group recently reported the adaptation of the BASF Basel process $^{8}$ to allow continuous flow acylation, arylation, alkylation to be reliably performed without concerns of clogging, regardless of the choice of solvent or concentration, by mediating them with bases that form ionic liquid conjugate acids upon protonation. 9 These simple substitution reactions are among the most frequently run in the pharmaceutical industry, ${ }^{10}$ and are thus particularly important to be able to conduct in automated synthesis platforms. Cross-coupling reactions are no less important, and their use in complex molecule synthesis continues to grow. ${ }^{11}$ The Suzuki-Miyaura reaction has been frequently reported in flow, in particular because the use of biphasic conditions allows for dissolution of organic and inorganic species present. ${ }^{22}$ Other cross-couplings are less straightforward to run continuously. In particular, the Buchwald-Hartwig amination is most frequently carried out using a strong inorganic base such as $\mathrm{NaOtBu}$ and forms insoluble halide salt $(\mathrm{NaX})$ byproducts (Scheme $\mathrm{iA}$ ). Continuous flow Buchwald-Hartwig aminations have been successfully achieved, for example, by sonicating the reactor channels to avoid aggregation of precipitate ${ }^{13}$ or by identifying effective biphasic conditions, ${ }^{14}$ among other strategies. ${ }^{15}$. While these solutions are promising, a more general and scalable strategy to allow Buchwald-Hartwig aminations to be reliably performed under homogeneous conditions would facilitate this reaction's use in continuous flow chemistry.

Scheme 1. Mild organic bases for cross coupling reactions in batch and flow.

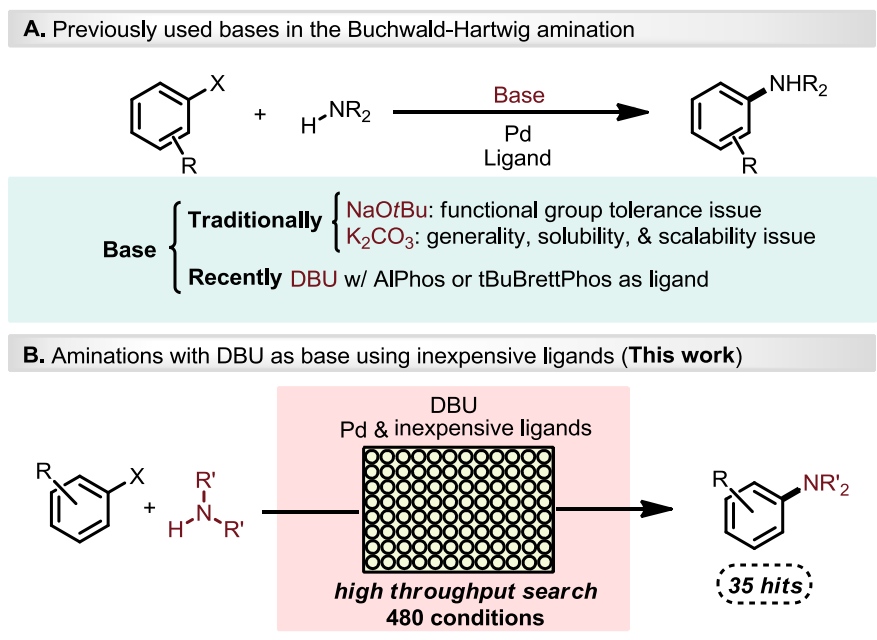

Continuous Buchwald-Hartwig, Mizoroki-Heck \& Sonogashra couplings

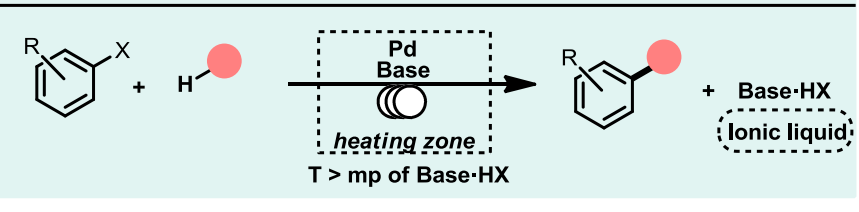

From the perspective of running Buchwald-Hartwig aminations in continuous flow, the use of organic bases that do not form precipitating solid byproducts is appealing. However, such reports are relatively rare. Examples using phosphazines and guanidines have recently been reported, ${ }^{16}$ though they are not economical for scale-up. 1,8-Diazabicyclo(5.4.0) undec-7ene (DBU), a milder, ionic liquid-forming amidine base, has been shown to work in microwave-irradiated aminations of organononaflates $;{ }^{17}$ however, experimental and DFT studies using this species suggested the barrier to the key deprotonation step is generally unachievably high. ${ }^{18}$ Towards the goal of enabling Pd-catalyzed amination to be performed with this relatively mild base to provide improved substrate scope, Buchwald and co-workers recently demonstrated that AlPhos, a designer phosphine ligand, facilitates the key deprotonation step by influencing the acidity of Pd-bound amines. ${ }^{19} \mathrm{Re}-$ searchers at Bristol-Myers Squibb realized a similar goal, ${ }^{20}$ noting the scale-up challenges associated with using insoluble inorganic bases, by using a combination of DBU as a base, NaTFA as a salt additive, and either Josiphos or t-BuBrettPhos as a ligand. These conditions were demonstrated to effectively 
and reproducibly enable a range of challenging BuchwaldHartwig aminations. While these contributions show great potential for the use of milder organic bases, the relatively high cost of the ligands used ${ }^{21}$ may hinder widespread adoption.

Towards the goal of expanding the range of important chemical reactions that can be reliably performed in continuous flow, we sought to explore Buchwald-Hartwig aminations with cost-effective ligands and DBU as an ionic liquid-forming base $\left(\mathrm{mp} \mathrm{DBU} \cdot \mathrm{HCl}=66^{\circ} \mathrm{C}\right)$. Numerous variables can influence the barrier of each key transition state of catalytic aminations, including the sterics and electronics of both coupling partners, the choice of solvent, the nature of the halide, and most importantly, the ligand. As a consequence, we anticipated that use of high throughput experimentation (HTE) ${ }^{22}$ may allow rapid and efficient exploration of diverse chemical reaction space to help identify an effective subset of conditions (Scheme $1 \mathrm{~B}$ ). Herein, we describe how several ligands, and XantPhos in particular, were identified for the efficient coupling of electron-poor aryl halides with nitrogen nucleophiles facilitated by DBU. As a milder alternative to inorganic bases like $\mathrm{KO} t$-Bu and LiHMDS, sensitive functionality like nitrile, nitro, and ketone groups are tolerated. As an ionic liquidforming base, the reactions can be readily implemented in a continuous flow process without concern for precipitate formation and reactor clogging. Lastly, the strategy of using ionic liquid-forming bases is demonstrated to be applicable to running continuous Mizoroki-Heck and Sonogashira reactions, further expanding the range of chemical reactions that can now be predictably and reliably run in flow (Scheme $1 \mathrm{~B}$ ).

The key variables of the Buchwald-Hartwig amination, such as the choice of halide, ligand, and solvent, are interrelated, and changes to one can impact the relative energies of multiple steps within the catalytic cycle. ${ }^{23}$ With this in mind, we performed a high throughput screen where each combination of six different organohalides, four amine nucleophiles, 10 commercially available ligands, and two solvents, all of which have been individually demonstrated in the literature to be effective choices. ${ }^{24}$ The metal catalyst $\left(\mathrm{Pd}_{2}(\mathrm{dba})_{3}\right)$, concentration $(0.1 \mathrm{M})$, reaction temperature $\left(100{ }^{\circ} \mathrm{C}\right)$, time $(18 \mathrm{~h})$, stoichiometry (1.2 equiv amine), and most importantly, base (DBU, 2 equiv) were fixed to keep the total number of experiments at a reasonable number.

These 48o experiments were setup in five 96-well plates using liquid-handling tools to facilitate material transfers. ${ }^{25}$ The outcome of the reaction was classified as a hit (product observed by GC-MS) or failure (no product observed) without rigorous quantification. ${ }^{26}$ In total, 35 unique hits were observed, suggesting that previous implications that DBU is an ineffective base may not be universally true. ${ }^{27}$ The selection of ligands, nucleophiles, organohalides, and solvents screened are provided in Scheme 2, ordered based on the frequency that they were observed to give a positive result in the high throughput screen. Several trends were observed. The electron-deficient organohalides 2-bromopyridine and 4-bromobenzonitrile were found to be effective more often than related electron-neutral species. Control experiments in the absence of catalyst confirmed that this observation was not related to nucleophilic aromatic substitution background reactivity. ${ }^{28}$ Of the amine nucleophiles tested, aniline and benzamide gave product more often than the more nucleophilic, less acidic benzylamine and morpholine. Both toluene and DMF were effective solvents, with DMF providing slightly more hits. Most excitingly, the inexpensive ligand XantPhos was found to be particularly promising. XantPhos has been previously observed to be an exceptionally effective ligand for Buchwald-Hartwig amination reactions; ${ }^{29}$ however, to our knowledge, its use with DBU as a homogeneous base has not been reported.

Scheme 2. Classification of varied parameters in HTE based on number of successful with each.

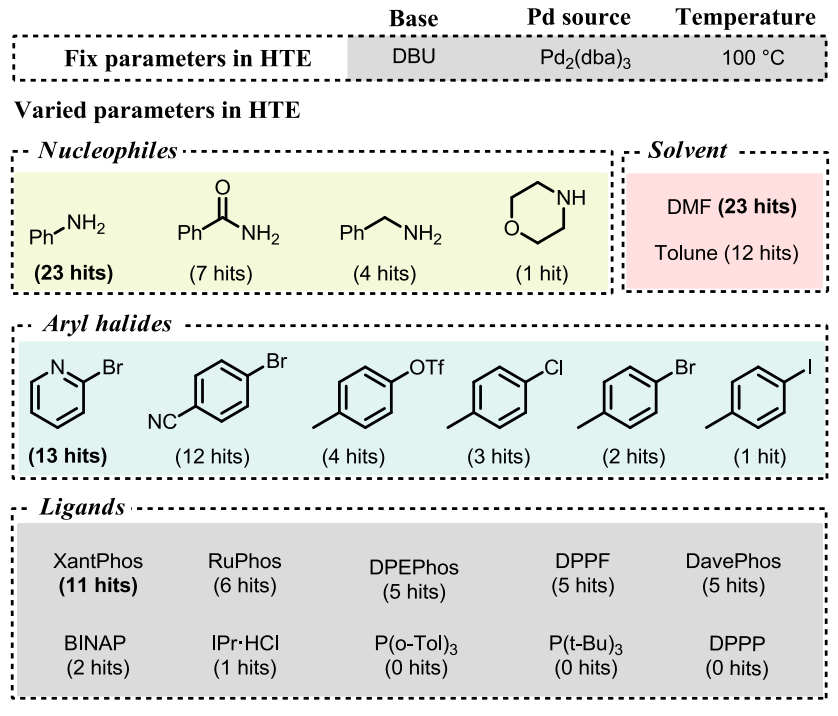

While individual optimization of each hit was beyond the scope of this article, we anticipate that many, if not most, of these experiments can be tuned to give synthetically viable yields. Towards confirming this hypothesis, a selection of successful conditions were reproduced as singleton experiments, quantified, and subject to brief reoptimization (Scheme 3). For example, the reaction between 4 -bromobenzonitrile (1) and benzamide (2) in the presence of XantPhos as a ligand and DMF as a solvent was observed to give a large product peak in crude GC analysis. Replication and quantification confirmed a yield of $83 \%$, indicating no further optimization was needed (Scheme $3 \mathrm{~A}$ ). Repeating the experiment with the aryl chloride analog instead resulted in a reduced $20 \%$ yield (Table 1 , entry 1), consistent with previous knowledge on the relative challenging of activating these stronger bonds.

Screening different Pd sources (entries 2-4) allowed identification of $[\mathrm{Pd}(\text { cinnamyl }) \mathrm{Cl}]_{2}$ as an improved choice over $\mathrm{Pd}_{2}(\mathrm{dba})_{3}$, Increasing the equivalents of nucleophile (entry 5 ), resulted in a slight improvement. Exploring alternative solvents (entries 6,7) and metal to ligand ratio (entry 8) to increase the yield of reaction. Lastly, decreasing the catalyst load provided $87 \%$ NMR yield ( $85 \%$ isolated).

Next, the coupling of aryl bromide $1 \mathrm{a}$ and benzyl amine 4 mediated by Xantphos as ligand, DBU as base, and DMF as solvent was replicated and quantified, providing 5 in $20 \%$ yield (Scheme $3 \mathrm{~B}$ ). Again, minor manipulations to the conditions enabled the identification of conditions that provide the desired coupling product in $75 \%$ NMR yield (70\% isolated) (See Table $\mathrm{S}_{5}$ in the SI for more information). 
Scheme 3. Identification and optimization of effective Buchwald-Hartwig aminations using DBU as a mild base.

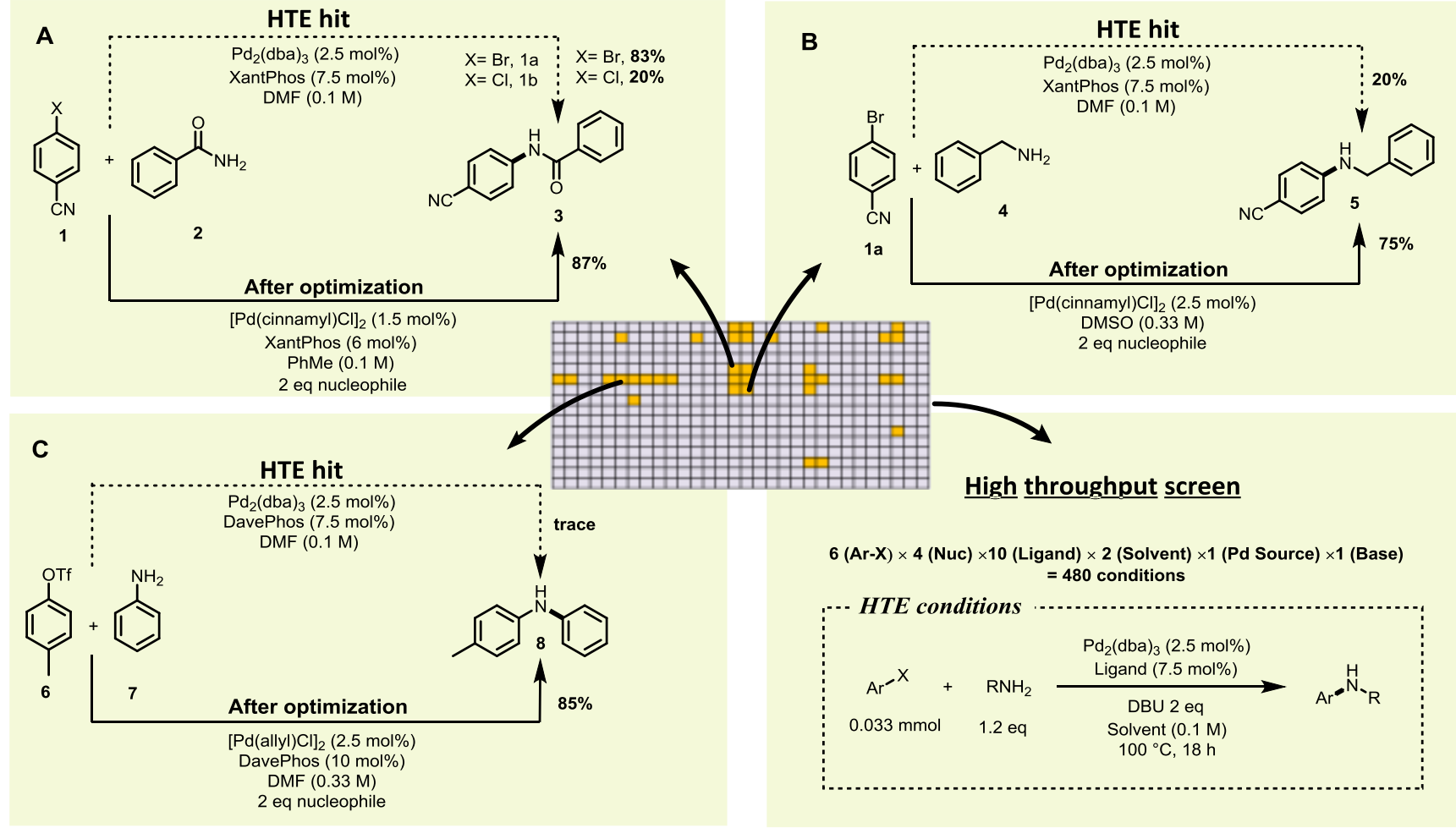

Table 1. Optimization of coupling amides with aryl halides in the presence of DBUa

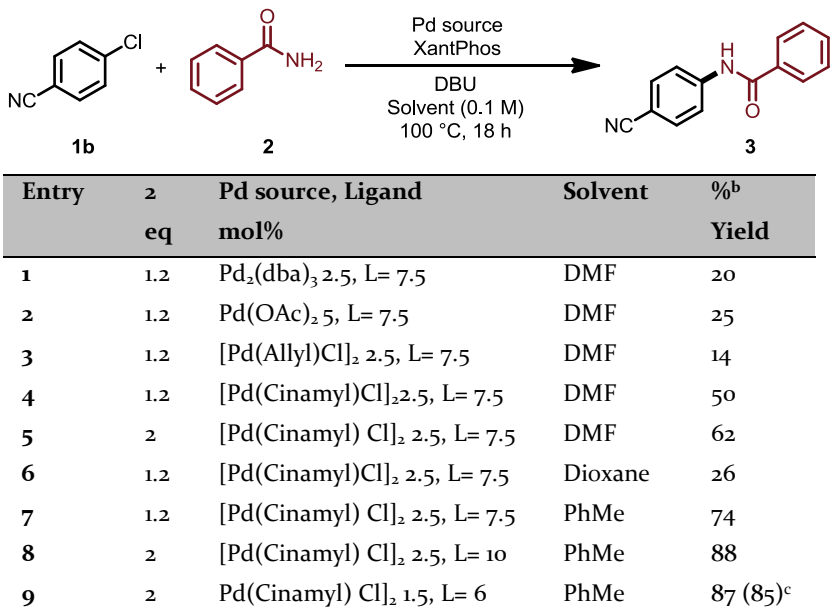

a Reactions performed on o.1 mmol scale. b Yield determined by ${ }^{1} \mathrm{H}$ NMR with 1,3,5-trimethoxy benzene as internal standard. ${ }^{c}$ Isolated yield.

The hit for the reaction of organotriflate 6 and aniline $\mathbf{7}$ was observed with DavePhos as ligand, albeit only in trace yield (Scheme ${ }_{3} \mathrm{C}$ ). Following a similar approach to that illustrated in Table 1 , a brief optimization resulted in identification of conditions that provided $85 \%$ NMR ( $85 \%$ isolated) yield of $\mathbf{8}$ (See Table S6 in the SI for more information)

Given the importance and relative rarity of cross-coupling reactions with amide nucleophiles, ${ }^{29,30}$ a brief reaction scope was evaluated using the reaction conditions identified for the coupling described in Table 1 (Scheme 4). The reaction was observed to be give amide 3 in good yield regardless of the choice of halide counterion. This was further confirmed by the successful coupling of 2-bromopyridine, 4-nitrochlorobenzene, and 2-iodobenzonitrile with varied amides to give products 9-11. Ketones with enolizable protons are particularly challenging functional groups when performing coupling reactions in the presence of aggressive bases such as KOtBu. With our conditions, 4-bromoacetophenone underwent smooth coupling to form 12 in $79 \%$ yield. Similarly, enantioenriched substrates with enolizable stereocenters are often racemized in the presence of strong base. Coupling of $\mathrm{N}$-acetylL-prolinamide with 4-bromobenzonitrile gave an excellent yield of the coupling product $\mathbf{1 3}$ with minimal epimerization (92\% yield, 94:6 e.r.). ${ }^{11}$ While this method is currently limited to electron-deficient organohalides, the low cost of XantPhos as a ligand, the mildness of DBU as a base, and the relative challenge of using amides as nucleophiles in these Pd-catalyzed coupling reactions make these conditions appealing when viable.

In addition to the ability to tolerate base-sensitive functional groups (nitrile, ketone, acidic stereocenter), one of the major benefits of using DBU as a base is in continuous flow chemistry. With the development of sophisticated flow synthesis machines and continuous multistep API manufacturing as major 
Scheme 4. Selected scope table for the Buchwald-Hartwig amination in the presence of DBU. ${ }^{\mathrm{a}}$
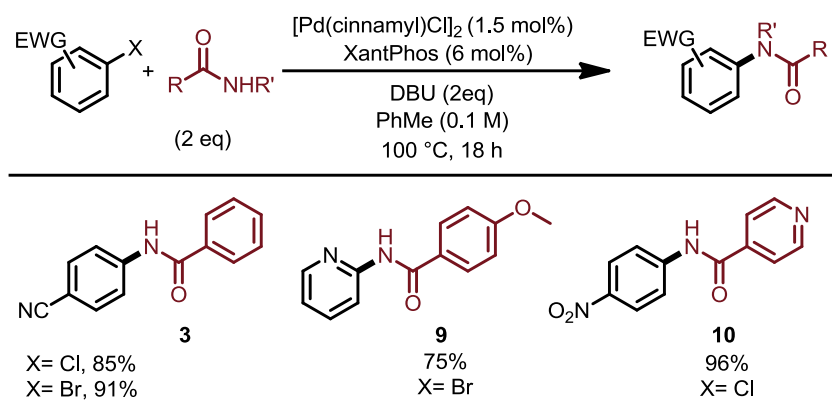
$\mathrm{X}=\mathrm{I}, 70 \%$
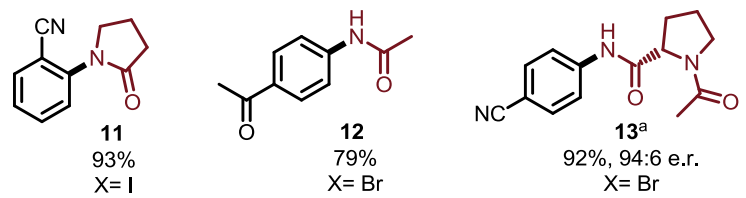

a Reactions run on $0.2 \mathrm{mmol}$ scale. Isolated yields given. ${ }^{b} \mathrm{Re}-$ action run for $2 \mathrm{~h}$.

goals in modern chemistry,3-6 it is important to ensure Buchwald-Hartwig aminations and related cross-coupling reactions can be readily implemented in flow without the hazard of clogging tubular reactors with precipitate. ${ }^{13^{-15}} \mathrm{DBU}$ is a well behaved liquid and the corresponding conjugate acids (DBU.HX) are ionic liquids, bearing melting points below 100 ${ }^{\circ} \mathrm{C}$, making it an appealing alternative to highly basic inorganic solvents. With this in mind, a selection of the BuchwaldHartwig aminations were carried out in a simple flow reactor using DBU as a base and XantPhos as a ligand. The XantPhos Pd G3 was selected due to efficient and rapid generation of the active catalytic species, and an elevated reaction temperature was chosen to ensure reactions reached completion in a reasonable residence time of 1 hour (Scheme 5). With these modifications, ${ }^{32}$ a selection of different organohalides and amide/aniline nucleophiles were coupled in $78-88 \%$ yield in a 1 $\mathrm{mL}$ tubular flow reactor with no precipitate formation, confirming this added benefit of using DBU as a base in aminations.

Lastly, we wished to extend this concept of using ionic liquid-forming bases in other cross-couplings. Mizoroki-Heck reactions are often performed with triethylamine as a base,33 which forms a high melting conjugate acid upon protonation. Successful examples of continuous flow Mizoroki-Heck reactions are primarily achieved by, for example, using dilute conditions, 34 and/or high temperatures with very polar solvents. 35 Like DBU, tributylamine forms ionic liquids upon protonation $\left(\mathrm{mp}\right.$ of $\left.\mathrm{NBu}_{3} \cdot \mathrm{HCl}=60{ }^{\circ} \mathrm{C}\right)$. With this simple change, high yielding Mizoroki-Heck reactions can be performed in flow with use of a typical nonpolar solvent (dioxane) and reaction temperature $\left(90{ }^{\circ} \mathrm{C}\right)$. Similarly, Sonogashira reactions commonly use triethylamine as a base and generate large quantities of precipitate. Reactions in flow have been achieved, for example, under high temperatures using high dilution with a polar solvent or by design of biphasic conditions. ${ }^{6}$ Simply using tributylamine as an ionic liquid-forming base instead enables straightforward adaptation of batch conditions to flow under reasonable temperature $\left(90^{\circ} \mathrm{C}\right)$ and concentration $(0.25$ $\mathrm{M}$ ) with a non-polar solvent (THF) (Scheme 5).37

In conclusion, we have explored the use of DBU as a base on a range of different Buchwald-Hartwig amination reactions using relatively inexpensive ligands. High throughput screening allowed identification of several conditions that could be rapidly optimized to provide synthetically viable yields, particularly when using XantPhos as ligand. In addition to providing an affordable and functional group tolerant set of conditions, the homogeneity of the reactions and the fact that the conjugate acid byproduct (DBU $\cdot \mathrm{HX}$ ) is an ionic liquid enables smooth translation into continuous flow conditions. A similar strategy using $\mathrm{NBu}_{3}$ as an ionic liquid-forming base enables continuous Mizoroki-Heck and Sonogashira couplings. Given the ubiquity of cross-coupling reactions, we believe this strategy will help expand the scope and utility of continuous automation platforms.

\section{ASSOCIATED CONTENT}

\section{AUTHOR INFORMATION}

\section{Corresponding Author}

stephen.newman@uottawa.ca

\section{ACKNOWLEDGEMENT}

Financial support for this work was provided by the University of Ottawa, the National Science and Engineering Research Council of Canada (NSERC), the Canada Research Chair program.). The Canadian Foundation for Innovation (CFI) and the Ontario Ministry of Economic Development and Innovation are thanked for essential infrastructure. We thank Apotex Pharma Inc. and the Ontario Centers of Excellence (OCE) for support via the Voucher of Innovation and Productivity program. S.K.K thanks Roxanne Clement for assistance with data generation via high-throughput experimentation, and Ryan J. Sullivan for his help with data processing. 
Scheme 5. Cross couplings in continuous flow using ionic liquid-forming bases.

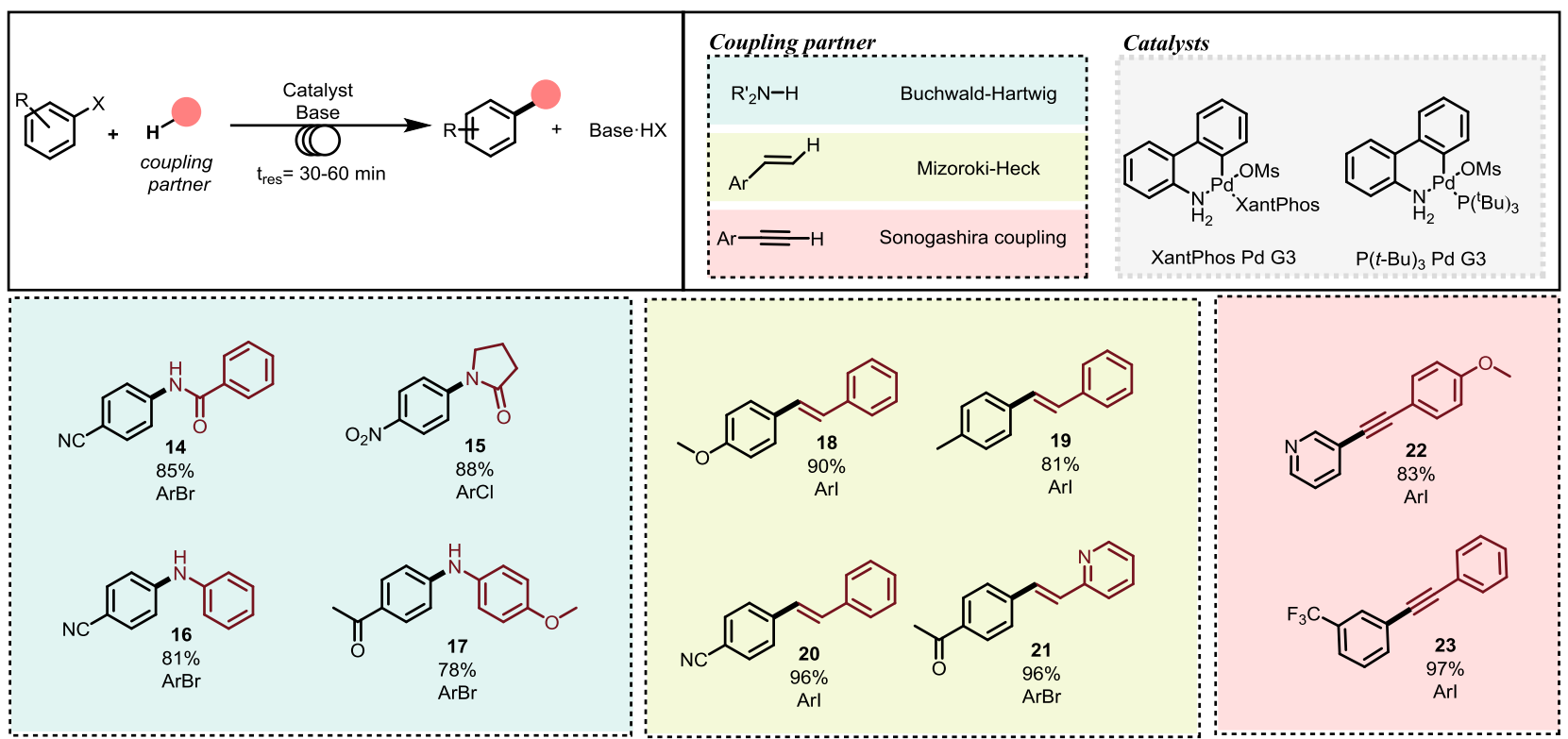

Buchwald-Hartwig amination conditions: 1 eq of aryl halide, 1 eq of amine, 2 eq of DBU and 5 mol\% of the " XantPhos Pd G3" using $\mathrm{MeCN} / \mathrm{PhMe}$ mixture as solvent in a $1 \mathrm{ml}$ stanless-steel flow reactor with 60 min residence time, $140{ }^{\circ} \mathrm{C}$. Mizoroki-Heck coupling: 1 eq of aryl halide, 1.5 eq of olefine, 3 eq of $\mathrm{NBu}_{3}$ and $3 \mathrm{~mol} \%$ of the "P(t-Bu$)_{3} \mathrm{Pd} \mathrm{G}_{3}$ " using dioxane as solvent in a $1 \mathrm{ml}$ PFA flow reactor with 60 min residence time, $90{ }^{\circ} \mathrm{C}$. Sonogashira coupling: 1 eq of aryl halide, 1.5 eq of alkyne, 3 eq of $\mathrm{NBu}_{3}$ and $2 \mathrm{~mol} \%$ of $\mathrm{Pd}(\mathrm{PPh})_{3}$, $\mathrm{CuI} 2 \mathrm{~mol} \%$ using THF as solvent in a $1 \mathrm{ml} \mathrm{PFA}$ flow reactor with 30 min residence time, $100{ }^{\circ} \mathrm{C}$. Isolated yields.

\section{REFERENCES}

Porta, R.; Benaglia, M.; Puglisi, A. Flow Chemistry: Recent Developments in the Synthesis of Pharmaceutical Products. Org. Process. Res. Dev. 2016, 20, 2-25.

(a) Peplow, M. Organic Synthesis: The Robo-Chemist. Nature. 2014, pp 20-22. (b) Reizman, B. J.; Wang, Y. M.; Buchwald, S. L.; Jensen, K. F. Suzuki-Miyaura CrossCoupling Optimization Enabled by Automated Feedback. React. Chem. Eng. 2016, 1, 658-666.

(a) McWilliams, J. C.; Allian, A. D.; Opalka, S. M.; May, S. A.; Journet, M.; Braden, T. M. The Evolving State of Continuous Processing in Pharmaceutical API Manufacturing. Org. Process Res. Dev. 2018, 22, 1143-1166. (b) May, S. A. Flow Chemistry, Continuous Processing, and Continuous Manufacturing: A Pharmaceutical Perspective. J. Flow Chem. 2017, 7, 137-145. (c) Bogdan, A. R.; Dombrowski, A. W. Emerging Trends in Flow Chemistry and Applications to the Pharmaceutical Industry. J. Med. Chem. 2019, ASAP. (d) Ürge, L.; Alcazar, J.; Huck, L.; Dormán, G. Recent Advances of Microfluidics Technologies in the Field of Medicinal Chemistry. In Annual Reports in Medicinal Chemistry; 2017; pp 87-147.

(4) Cole, K. P.; Groh, J. M. C.; Johnson, M. D.; Burcham, C. L.; Campbell, B. M.; Diseroad, W. D.; Heller, M. R.; Howell, J. R.; Kallman, N. J.; Koenig, T. M.; et al. Kilogram-Scale Prexasertib Monolactate Monohydrate Synthesis under Continuous-Flow CGMP Conditions. Science. 2017, 356, 1144-1150.
Mascia, S.; Heider, P. L.; Zhang, H.; Lakerveld, R.; Benyahia, B.; Barton, P. I.; Braatz, R. D.; Cooney, C. L.; Evans, J. M. B.; Jamison, T. F.; et al. End-to-End Continuous Manufacturing of Pharmaceuticals: Integrated Synthesis, Purification, and Final Dosage Formation. Angew. Chem., Int. Ed. 2013, 52, $12359-12363$.

(a) Bédard, A.-C.; Adamo, A.; Aroh, K. C.; Russell, M. G.; Bedermann, A. A.; Torosian, J.; Yue, B.; Jensen, K. F.; Jamison, T. F. Reconfigurable System for Automated Optimization of Diverse Chemical Reactions. Science. 2018, 361, 1220-1225. (b) Adamo, A.; Beingessner, R. L.; Behnam, M.; Chen, J.; Jamison, T. F.; Jensen, K. F.; Monbaliu, J. C. M.; Myerson, A. S.; Revalor, E. M.; Snead, D. R.; et al. OnDemand Continuous-Flow Production of Pharmaceuticals in a Compact, Reconfigurable System. Science. 2016, 352, 61-67. (c) Li, J.; Ballmer, S. G.; Gillis, E. P.; Fujii, S.; Schmidt, M. J.; Palazzolo, A. M. E.; Lehmann, J. W.; Morehouse, G. F.; Burke, M. D. Synthesis of Many Different Types of Organic Small Molecules Using One Automated Process. Science. 2015, 347, 1221-1226.

(7) (a) Hartman, R. L.; Naber, J. R.; Zaborenko, N.; Buchwald, S L.; Jensen, K. F. Overcoming the Challenges of Solid Bridging and Constriction during Pd-Catalyzed C-N Bond Formation in Microreactors. Org. Process Res. Dev. 2010, 14, 1347-1357. (b) Jensen, K. F.; Kuhn, S.; Noel, T.; Gu, L.; Heider, P. L. A Teflon Microreactor with Integrated Piezoelectric Actuator to Handle Solid Forming Reactions. Lab Chip 2o11, 11, 24882492. (c) Hartman, R. L. Managing Solids in Microreactors for the Upstream Continuous Processing of Fine Chemicals. Org. Process Res. Dev. 2012, No. 16, 870-887. (d) Wu, K.; 
Kuhn, S. Strategies for Solids Handling in Microreactors. Chim. Oggi/Chemistry Today 2014, 32, 62-66. (e) Chen, Y.; Sabio, J. C.; Hartman, R. L. When Solids Stop Flow Chemistry in Commercial Tubing. J. Flow Chem. 2015, 5, 166-171. (f) Kwak, J. S.; Zhang, W.; Tsoy, D.; Hunter, H. N.; Mallik, D.; Organ, M. G. A Multiconfiguration Valve for Uninterrupted Sampling from Heterogeneous Slurries: An Application to Flow Chemistry. Org. Process Res. Dev. 2017, 21, 1051-1058. (g) Poe, S. L.; Cummings, M. A.; Haaf, M. P.; McQuade, D. T. Solving the Clogging Problem: Precipitate-Forming Reactions in Flow. Angew. Chem., Int. Ed. 2006, 45, 15441548. (h) Isoni, V.; Mendoza, K.; Lim, E.; Teoh, S. K. Screwing $\mathrm{NaBH}_{4}$ through a Barrel without a Bang: A Kneaded Alternative to Fed-Batch Carbonyl Reductions. Org. Process Res. Dev. 2017, 21, 992-1002. (i) Schoenitz, M.; Grundemann, L.; Augustin, W.; Scholl, S. Fouling in Microstructured Devices: A Review. Chem. Commun. 2015, 51, 8213-8228. (j) A. Lapkin, K. Loponov, G. Tomaiuolo andS. Guido, inSustainable Flow Chemistry: Methods andApplications, ed. L. Vaccaro, Wiley-VCH Verlag GmbH \& Co.KGaA, Weinheim, 2017

(a) Seddon, K. R. Ionic Liquids: A Taste of the Future. Nat. Mater. 2003, 2, 363-365. (b) M. Maase and K. Massonne. In Ionic Liquids IIIB:Fundamentals, Progress, Challenges, and Opportunities, ed.R. D. Rogers and K. R. Seddon, American Chemical Society, Washington, 2005, ch. 10, 126-132.

Kashani, S.; Sullivan, R. J.; Andersen, M.; Newman, S. G. Overcoming Solid Handling Issues in Continuous Flow Substitution Reactions through Ionic Liquid Formation. Green Chem. 2018, 20, 1748-1753.

(a) Schneider, N.; Lowe, D. M.; Sayle, R. A.; Tarselli, M. A.; Landrum, G. A. Big Data from Pharmaceutical Patents: A Computational Analysis of Medicinal Chemists Bread and Butter. J. Med. Chem. 2016, 59, 4385-4402. (b) Brown, D. G.; Boström, J. Analysis of Past and Present Synthetic Methodologies on Medicinal Chemistry: Where Have All the New Reactions Gone? J. Med. Chem. 2o16, 59, 4443-4458. (c) Roughley, S. D.; Jordan, A. M. The Medicinal Chemist's Toolbox: An Analysis of Reactions Used in the Pursuit of Drug Candidates. J. Med. Chem. 2011, 54, 3451-3479. (d) Torborg, C.; Beller, M. Recent Applications of PalladiumCatalyzed Coupling Reactions in the Pharmaceutical, Agrochemical, and Fine Chemical Industries. Adv. Synth. Catal. 2009, 351, 3027-304.

(11) Cooper, T. W. J.; Campbell, I. B.; MacDonald, S. J. F. Factors Determining the Selection of Organic Reactions by Medicinal Chemists and the Use of These Reactions in Arrays (Small Focused Libraries). Angew. Chem., Int. Ed. 2010, 49, $8082-8091$

(12) (a) Noël, T.; Musacchio, A. J. Suzuki-Miyaura CrossCoupling of Heteroaryl Halides and Arylboronic Acids in Continuous Flow. Org. Lett. 2011, 13, 5180-5183. (b) Noël, T.; Kuhn, S.; Musacchio, A. J.; Jensen, K. F.; Buchwald, S. L. Suzuki-Miyaura Cross-Coupling Reactions in Flow: Multistep Synthesis Enabled by a Microfluidic Extraction. Angew. Chem., Int. Ed. 2011, 50, 5043-5046. (c) Uozumi, Y.; Yamada, Y. M. A.; Beppu, T.; Fukuyama, N.; Ueno, M.; Kitamori, T. Instantaneous Carbon-Carbon Bond Formation Using a Microchannel Reactor with a Catalytic Membrane. J. Am. Chem. Soc. 2006, 128, 15994-15995. (d) Sieber, J. D.; Buono, F.; Brusoe, A.; Desrosiers, J. N.; Haddad, N.; Lorenz, J. C.; Xu, Y.; Wu, H.; Zhang, L.; Han, Z. S.; et al. Application of a Preformed Pd-BIDIME Precatalyst to Suzuki-Miyaura Cross-Coupling Reaction in Flow. J. Org. Chem. 2019, 84, 4926-4931. (e) Pascanu, V.; Hansen, P. R.; Bermejo Gómez, A.; Ayats, C.; Platero-Prats, A. E.; Johansson, M. J.; Pericàs,
M.; Martín-Matute, B. Highly Functionalized Biaryls via Suzuki-Miyaura Cross-Coupling Catalyzed by Pd@MOF under Batch and Continuous Flow Regimes. ChemSusChem 2015, 8, 123-130. (f) Len, C.; Bruniaux, S.; Delbecq, F.; Parmar, V. Palladium-Catalyzed Suzuki-Miyaura Cross-Coupling in Continuous Flow. Catalysts 2o17, 7, 146.

(13) (a) Noël, T.; Naber, J. R.; Hartman, R. L.; Mcmullen, J. P.; Jensen, K. F.; Buchwald, S. L. Palladium-Catalyzed Amination Reactions in Flow: Overcoming the Challenges of Clogging via Acoustic Irradiation. Chem. Sci. 2011, 2, 287290. (b) Yaseneva, P.; Hodgson, P.; Zakrzewski, J.; Falß, S.; Meadows, R. E.; Lapkin, A. A. Continuous Flow BuchwaldHartwig Amination of a Pharmaceutical Intermediate. React. Chem. Eng. 2016, 1, 229-238.

(14) Naber, J. R.; Buchwald, S. L. Packed-Bed Reactors for Continuous-Flow C-N Cross-Coupling. Angew. Chem., Int. Ed. 2010, 49 (49), 9469-9474.

(a) Hopkin, M. D.; Baxendale, I. R.; Ley, S. V. A Flow-Based Synthesis of Imatinib: The API of Gleevec. Chem. Commun. 2010, 46, 2450-2452. (b) Mauger, C.; Buisine, O.; Caravieilhes, S.; Mignani, G. Successful Application of Microstructured Continuous Reactor in the Palladium Catalysed Aromatic Amination. J. Organomet. Chem. 2005, 690 (16), 3627-3629. (c) Pommella, A.; Tomaiuolo, G.; Chartoire, A.; Caserta, S.; Toscano, G.; Nolan, S. P.; Guido, S. Palladium-N-Heterocyclic Carbene (NHC) Catalyzed C-N Bond Formation in a Continuous Flow Microreactor. Effect of Process Parameters and Comparison with Batch Operation. Chem. Eng. J. 2013, 223, 578-583. (d) Falß, S.; Tomaiuolo, G.; Perazzo, A.; Hodgson, P.; Yaseneva, P.; Zakrzewski, J.; Guido, S.; Lapkin, A.; Woodward, R.; Meadows, R. E. A Continuous Process for Buchwald-Hartwig Amination at Micro-, Lab-, and Mesoscale Using a Novel Reactor Concept. Org. Process Res. Dev. 2016, 20, 558-567. (e) Perazzo, A.; Tomaiuolo, G.; Sicignano, L.; Toscano, G.; Meadows, R. E.; Nolan, S. P.; Guido, S. A Microfluidic Approach for Flexible and Efficient Operation of a CrossCoupling Reactive Flow. RSC Adv. 2015, 5, 63786-63792. (f) Noël, T.; Buchwald, S. L. Cross-Coupling in Flow. Chem. Soc. Rev. 2011, 40, 5010-5029. (g) Pithani, S.; Malmgren, M.; Aurell, C.-J.; Nikitidis, G.; Friis, S. D. Biphasic Aqueous Reaction Conditions for Process-Friendly PalladiumCatalyzed C-N Cross-Coupling of Aryl Amines. Org. Process Res. Dev. 2019, 23, 1752-1757.

(16) (a) Buitrago Santanilla, A.; Christensen, M.; Campeau, L. C.; Davies, I. W.; Dreher, S. D. P2Et Phosphazene: A Mild, Functional Group Tolerant Base for Soluble, Room Temperature Pd-Catalyzed C-N, C-O, and C-C CrossCoupling Reactions. Org. Lett. 2015, 17, 3370-3373. (b) Santanilla, A. B.; Regalado, E. L.; Pereira, T.; Shevlin, M.; Bateman, K.; Campeau, L. C.; Schneeweis, J.; Berritt, S.; Shi, Z. C.; Nantermet, P.; et al. Nanomole-Scale High-Throughput Chemistry for the Synthesis of Complex Molecules. Science. 2015, 347, 49-53. (c) Ahneman, D. T.; Estrada, J. G.; Lin, S.; Dreher, S. D.; Doyle, A. G. Predicting Reaction Performance in C-N Cross-Coupling Using Machine Learning. Science. 2018, 36o, 186-19o. (d) Uehling, M. R.; King, R. P.; Krska, S. W.; Cernak, T.; Buchwald, S. L. Organic Chemistry: Pharmaceutical Diversification via Palladium Oxidative Addition Complexes. Science. 2019, 363, 405-408.

(17) Tundel, R. E.; Anderson, K. W.; Buchwald, S. L. Expedited Palladium-Catalyzed Amination of Aryl Nonaflates through the Use of Microwave-Irradiation and Soluble Organic Amine Bases. J. Org. Chem. 20o6, 71, 430-433.

(18) (a) Hoi, K. H.; Çalimsiz, S.; Froese, R. D. J.; Hopkinson, A. C.; 
Organ, M. G. Amination with Pd-NHC Complexes: Rate and Computational Studies on the Effects of the Oxidative Addition Partner. Chem. - A Eur. J. 2011, 17, 3086-3090.

(a) Dennis, J. M.; White, N. A.; Liu, R. Y.; Buchwald, S. L. Breaking the Base Barrier: An Electron-Deficient Palladium Catalyst Enables the Use of a Common Soluble Base in C-N Coupling. J. Am. Chem. Soc. 2018, 140, 4721-4725. (b) Dennis, J. M.; White, N. A.; Liu, R. Y.; Buchwald, S. L. Pd-Catalyzed C-N Coupling Reactions Facilitated by Organic Bases: Mechanistic Investigation Leads to Enhanced Reactivity in the Arylation of Weakly Binding Amines. ACS Catal. 2019, 9, 3822-3830. (C) Baumgartner, L. M.; Dennis, J. M.; White, N. A.; Buchwald, S. L.; Jensen, K. F. Use of a Droplet Platform To Optimize Pd-Catalyzed C-N Coupling Reactions Promoted by Organic Bases. Org. Process Res. Dev. 2019, 23 (8), 1594-1601.

(20) Beutner, G. L.; Coombs, J. R.; Green, R. A.; Inankur, B.; Lin, D.; Qiu. J.; Roberts, F.; Simmons, E. M.; R. Wisniewski, S. R. Palladium-Catalyzed Amidation and Amination of (Hetero)arylChlorides under Homogeneous Conditions Enabled by a SolubleDBU/NaTFA Dual-Base System. Org. Process Res. Dev. ASAP.

(21) Note: Current prices from Strem: $0.84 \$ / \mathrm{mg}$ for JosiPhos, 1.1 $\$ / \mathrm{mg}$ for $t$-BuBrettPhos, and $1 \$ / \mathrm{mg}$ for AlPhos.

(22) (a) Collins, K. D.; Glorius, F. A Robustness Screen for the Rapid Assessment of Chemical Reactions. Nat. Chem. 2o13, 5, 597-6o1. (b) Isbrandt, E. S.; Sullivan, R. J.; Newman, S. G. High Throughput Strategies for the Discovery and Optimization of Catalytic Reactions. Angew. Chem., Int. Ed. 2019, 58, 7180-7191. (c) Allen, C. L.; Leitch, D. C.; Anson, M. S.; Zajac, M. A. The Power and Accessibility of HighThroughput Methods for Catalysis Research. Nat. Catal. 2019, 2, 2-4. (d) Shevlin, M. Practical HighThroughput Experimentation for Chemists. ACS Med. Chem. Lett. 2017, 8, 601-607.

(23) (a) Hoi, K. H.; Organ, M. G. Potassium 2,2,5,7,8Pentamethylchroman-6-Oxide: A Rationally Designed Base for Pd-Catalysed Amination. Chem. - A Eur. J. 2012, 18, 804 807. (b)look at 18a (c) Hoi, K. H.; Çalimsiz, S.; Froese, R. D. J.; Hopkinson, A. C.; Organ, M. G. Amination with Pd-NHC Complexes: Rate and Computational Studies on the Effects of the Oxidative Addition Partner. Chem. - A Eur. J. 2o11, 17, 3086-3090.

(24) (a) Old, D. W.; Wolfe, J. P.; Buchwald, S. L. A Highly Active Catalyst for Palladium-Catalyzed Cross-Coupling Reactions: Room-Temperature Suzuki Couplings and Animation of Unactivated Aryl Chlorides [22]. J. Am. Chem. Soc. 1998, 120, 9722-9723. (b) Huang, X.; Anderson, K. W.; Zim, D.; Jiang, L.; Klapars, A.; Buchwald, S. L. Expanding Pd-Catalyzed C-N Bond-Forming Processes: The First Amidation of Aryl Sulfonates, Aqueous Amination, and Complementarity with Cu-Catalyzed Reactions. J. Am. Chem. Soc. 2003, 125, 66536655. (c) Yin, J.; Buchwald, S. L. Pd-Catalyzed Intermolecular Amidation of Aryl Halides: The Discovery That Xantphos Can Be Trans-Chelating in a Palladium Complex. J. Am. Chem. Soc. 2002, 124, 6043-6048. (d) Yang, B. H.; Buchwald, S. L. The Development of Efficient Protocols for the Palladium-Catalyzed Cyclization Reactions of Secondary Amides and Carbamates. Org. Lett. 2002, 1, 35-38. (e) Yang, B. H.; Buchwald, S. L. Palladium-Catalyzed Amination of Aryl Halides and Sulfonates. J. Organomet. Chem. 1999, 576, 125-146. (f) Wagaw, S.; Buchwald, S. L. The Synthesis of Aminopyridines: A Method Employing Palladium-Catalyzed Carbon-Nitrogen Bond Formation. J. Org. Chem. 1996, 61, 7240-7241. (g) Driver, M. S.; Hartwig, J. F. A Second-
Generation Catalyst for Aryl Halide Amination: Mixed Secondary Amines from Aryl Halides and Primary Amines Catalyzed by (DPPF)PdCl2. J. Am. Chem. Soc. 1996, 118, 72177218. (h) Wagaw, S.; Rennels, R. A.; Buchwald, S. L. Palladium-Catalyzed Coupling of Optically Active Amines with Aryl Bromides. J. Am. Chem. Soc. 1997, 119, 8451-8458. (i) Hartwig, J. F.; Kawatsura, M.; Hauck, S. I.; Shaughnessy, K. H.; Alcazar-Roman, L. M. Room-Temperature PalladiumCatalyzed Amination of Aryl Bromides and Chlorides and Extended Scope of Aromatic C-N Bond Formation with a Commercial Ligand. J. Org. Chem. 1999, 64, 5575-558o. (j) Lee, S.; Jørgensen, M.; Hartwig, J. F. Palladium-Catalyzed Synthesis of Arylamines from Aryl Halides and Lithium Bis(Trimethylsilyl)Amide as an Ammonia Equivalent. Org. Lett. 2001, 3, 2729-2732. (k) Fairlamb, I. J. S.; Kapdi, A. R.; Lee, A. F.; McGlacken, G. P.; Weissburger, F.; De Vries, A. H. M.; Schmieder-Van De Vondervoort, L. Exploiting Noninnocent (E,E)-Dibenzylideneacetone (Dba) Effects in Palladium(o)-Mediated Cross-Coupling Reactions: Modulation of the Electronic Properties of Dba Affects Catalyst Activity and Stability in Ligand and Ligand-Free Reaction Systems. Chem. - A Eur. J. 20o6, 12, 8750 - 8761. (l) Nishiyama, M.; Yamamoto, T.; Koie, Y. Synthesis of NArylpiperazines from ,Butylphosphine Catalyst. Tetrahedron Lett. 1998, 39, 617-620. (m) Wolfe, J. P.; Wagaw, S.; Buchwald, S. L. An Improved Catalyst System for Aromatic Carbon-Nitrogen Bond Formation: The Possible Involvement of Bis(Phosphine) Palladium Complexes as Key Intermediates. J. Am. Chem. Soc. 1996, 118, 7215-7216. (n) Louie, J.; Driver, M. S.; Hamann, B. C.; Hartwig, J. F. Palladium-Catalyzed Amination of Aryl Triflates and Importance of Triflate Addition Rate. J. Org. Chem. 1997, 62, 1268-1273. (o) Ackermann, L. General and Efficient Indole Syntheses Based on Catalytic Amination Reactions. Org. Lett. 2005, 7, 439-442.

(25) Freeslate $\mathrm{CM}_{3}$ automated platform was used to conduct experiments, housed inside a glovebox filled with $\mathrm{N}_{2}$ to see examples see this citation: Lee, G. M.; Clément, R.; Baker, R. T. High-Throughput Evaluation of in Situ-Generated Cobalt(III) Catalysts for Acyl Fluoride Synthesis. Catal. Sci. Technol. 2017, 7 (21), 4996-5003.

(26) Internal standard was added for approximating yield by GCMS. See section 2.1 and 2.2 in the Supporting Information for further details on the methodology used.

(27) Sunesson, Y.; Limé, E.; Nilsson Lill, S. O.; Meadows, R. E.; Norrby, P. O. Role of the Base in Buchwald-Hartwig Amination. J. Org. Chem. 2014, 79, 11961-11969.

(28) Expected background reaction was the reaction between amines with good nucleophilic character such as morpholine and benzylamine in the presence of electron-poor aryl halides such as 2-bromopyridine and 4-bromobenzonitrile through $\mathrm{S}_{\mathrm{N}} \mathrm{Ar}$ mechanism instead of Buchwald-Hartwig amination. Control reactions in batch and the data from HTE proves that $\mathrm{S}_{\mathrm{N}} \mathrm{Ar}$ does not happen.

(29) (a) Ruiz-Castillo, P.; Buchwald, S. L. Applications of Palladium-Catalyzed C-N Cross-Coupling Reactions. Chem. Rev. 2016, 116, 12564-12649.

(30) Sharif, S.; Day, J.; Hunter, H. N.; Lu, Y.; Mitchell, D.; Rodriguez, M. J.; Organ, M. G. Cross-Coupling of Primary Amides to Aryl and Heteroaryl Partners Using (DiMeIHept $\mathrm{Cl}) \mathrm{Pd}$ Promoted by Trialkylboranes or $\mathrm{B}\left(\mathrm{C}_{6} \mathrm{~F}_{5}\right)$ 3. J. Am. Chem. Soc. 2017, 139, 18436-18439. (c) Yin, J.; Buchwald, S. L. Palladium-Catalyzed Intermolecular Coupling of Aryl Halides and Amides. Org. Lett. 200o, 2, 1101-1104. . 
(31) Replicating this reaction with $\mathrm{KOtBu}$ as base resulted in o\% yield of 13, instead forming the nucleophilic aromatic substitution product between the organohalide and the tertbutoxide nucleophile was observed.

(32) For praparation of the $\mathrm{Pd} \mathrm{G}_{3}$ precatalysts see this paper: Bruno, N. C.; Tudge, M. T.; Buchwald, S. L. Design and Preparation of New Palladium Precatalysts for C-C and C-N Cross-Coupling Reactions. Chem. Sci. 2013, 4, 916-920. https://doi.org/10.1039/c2sc20903a.

(33) (a) Liu, S.; Berry, N.; Thomson, N.; Pettman, A.; Hyder, Z.; Mo, J.; Xiao, J. Pd-MBDPP-Catalyzed Regioselective Internal Arylation of Electron-Rich Olefins by Aryl Halides. J. Org. Chem. 2oo6, 71, 7467-7470. (b) Wang, Z.; Feng, X.; Fang, W.; $\mathrm{Tu}, \mathrm{T}$. Efficient Aqueous-Phase Heck Reaction Catalyzed by a Robust Hydrophilic Pyridine-Bridged Bisbenzimidazolylidene-Palladium Pincer Complex. Synlett 2011, 7, 951-954. (c) Lipshutz, B. H.; Taft, B. R. Heck Couplings at Room Temperature in Nanometer Aqueous Micelles. Org. Lett. 2008, 10, 1329-1332. (d) McConville, M.; Saidi, O.; Blacker, J.; Xiao, J. Regioselective Heck Vinylation of Electron-Rich Olefins with Vinyl Halides: Is the Neutral Pathway in Operation? J. Org. Chem. 2oo9, 74, 2692-2698. (e) Martin, S. E. S.; Watson, D. A. Preparation of Vinyl Silyl Ethers and Disiloxanes via the Silyl-Heck Reaction of Silyl Ditriflates. J. Am. Chem. Soc. 2013, 135, 13330-13333.

(34) McMullen, J. P.; Stone, M. T.; Buchwald, S. L.; Jensen, K. F. An Integrated Microreactor System for Self-Optimization of a Heck Reaction: From Micro-to Mesoscale Flow Systems. Angew. Chem., Int. Ed. 2010, 49, 7076-7080.
(35) (a) Achanta, S.; Liautard, V.; Paugh, R.; Organ, M. G. The Development of a General Strategy for the Synthesis of Tyramine-Based Natural Products by Using Continuous Flow Techniques. Chem. - A Eur. J. 2010, 16, 12797-1280o. (b) Nikbin, N.; Ladlow, M.; Ley, S. V. Continuous Flow LigandFree Heck Reactions Using Monolithic Pd [o] Nanoparticles. Org. Process Res. Dev. 2007, 11, 458-462. (c) Monguchi, Y.; Ichikawa, T.; Yamada, T.; Sawama, Y.; Sajiki, H. ContinuousFlow Suzuki-Miyaura and Mizoroki-Heck Reactions under Microwave Heating Conditions. Chem. Rec. 2019, 19, 3-14.

(36) (a) Shu, W.; Buchwald, S. L. Use of Precatalysts Greatly Facilitate Palladium-Catalyzed Alkynylations in Batch and Continuous-Flow Conditions. Chem. Sci. 2011, 2, 2321-2325. (b) Tan, L. M.; Sem, Z. Y.; Chong, W. Y.; Liu, X.; Hendra; Kwan, W. L.; Lee, C. L. K. Continuous Flow Sonogashira C-C Coupling Using a Heterogeneous Palladium-Copper Dual Reactor. Org. Lett. 2013, 15, 65-67.

（37） (a) Atta, A. K.; Kim, S. B.; Heo, J.; Cho, D. G. Hg(II)-Mediated Intramolecular Cyclization Reaction in Aqueous Media and Its Application as $\mathrm{Hg}$ (II) Selective Indicator. Org. Lett. 2013, 15, 1072-1075. (a) (1) Borcsek, B.; Bene, G.; Szirbik, G.; Dormán, G.; Jones, R.; Ürge, L.; Darvas, F. Rapid Catalyst Evaluation for Sonogashira Coupling in Continuous Flow. Arkivoc 2012, 2012 (5), 186-195. 